\title{
Percutaneous balloon mitral valvuloplasty in severe restenosis of the mitral valve: Analysis of factors affecting the short term outcomes - A single center experience
}

\author{
*Srinivas Bhyravavajhala ${ }^{1}$, Keerthika Ravella ${ }^{2}$, Sreekanth Yerram ${ }^{3}$, \\ Siva Prasad Akula ${ }^{4}$, Damera Seshagiri Rao ${ }^{5}$ \\ ${ }^{1}$ Associate professor, Department of Cardiology, Nizam's institute of medical sciences \\ ${ }^{2}$ Senior resident, Department of Cardiology, Nizam's institute of medical sciences \\ ${ }^{3}$ Assistant professor, Department of Cardiology, Nizam's institute of medical sciences \\ ${ }^{4}$ Associate professor, Department of Cardiology, Nizam's institute of medical sciences \\ ${ }^{5}$ Professor, Department of Cardiology, Nizam's institute of medical sciences \\ *Corresponding author: * Srinivas Bhyravavajhala
}

\begin{abstract}
:
Introduction: Rheumatic heart disease (RHD) is still a major problem in developing countries, with mitral stenosis being the most frequent manifestation. Percutaneous mitral valvuloplasty has emerged as the procedure of choice in most patients with symptomatic mitral stenosis. Late recurrence of symptoms after the procedure is mostly related to mitral restenosis. A few reports are available about percutaneous valvuloplasty in restenosis of the mitral valve, but factors predicting the outcomes are not clear. In this study we tried to explore clinical characters and short term out-comes of percutaneous balloon mitral valvuloplasty in symptomatic severe mitral restenosis.

Materials and methods: Thirty five consecutive inpatients who underwent percutaneous balloon mitral valvuloplasty (PBMV) for symptomatic and severe mitral restenosis after previous surgery or valvuloplasty were included in this single center prospective study. Comprehensive transthoracic and transesophageal echocardiographic examination was done and mitral valve morphology was assessed. To define more accurately the relation between the mechanism of restenosis and the immediate results of repeat PBMV, we focused on commissural morphology and sub classified patients into 2 groups: patients with bilateral fused commissures and patients with either unilateral or bilateral split commissures. PBMV was done according to standard technique. Procedural success was defined as an increase of $50 \%$ of mitral valve area or a final area of $1.5 \mathrm{~cm}^{2}$, with no more than one grade increment in MR severity assessed by echocardiography 24 hours after the procedure. Patients with persistent left atrial or left atrial appendage thrombus, more than moderate mitral regurgitation $(M R)$, severe or bicommissural calcification, severe concomitant aortic valve disease, severe organic tricuspid stenosis, severe concomitant coronary artery disease requiring bypass surgery and severe subvalve disease were excluded from the study.

Results: A total of 35 patients were enrolled into the study (mean age $37.51 \pm 10.29$ years). Of these 35 patients, $22(62.8 \%)$ were males and $13(37.14 \%)$ were females. patients were divided into two groups as group 1 (bilaterally fused commissure) and group 2 (one split commissure) Bilateral fused commisures were in 7 patients and either of commissure was split in remaining 28 patients. Mean age of the study population was $37.51 \pm 10.29$ years. Mean mitral valve area was $1.02 \pm 0.15\left(\mathrm{~cm}^{2}\right)$ and $1.07 \pm 0.19\left(\mathrm{~cm}^{2}\right)$ in either commissure split and bilateral fused commisures groups respectively $(p=0.23)$. Mean mitral valve gradient, peak mitral valve gradient, systolic pulmonary artery pressure and LA size were not statistically significant between two groups. LA thrombus was absent in both the groups. average Post PTMC mitral valve area in bilateral fused commisures group was $1.77 \pm 0.09 \mathrm{~cm}^{2}$ and in either of commissure split group was $1.52 \pm 0.42 \mathrm{~cm}^{2}(p=0.001)$. Mean mitral valve gradients were $5.04 \pm 1.69 \mathrm{mmHg}$ and $3.71 \pm 4.08 \mathrm{mmHg}(p=0.025)$ and peak mitral valve gradient was $9.54 \pm 2.52$ and $7.14 \pm 3.39(p=0.02)$ which are statistically significant in either commissure split and bilateral fused commisures group respectively. There was no statistically significant difference in, systolic pulmonary artery pressures between the two groups. In the present study optimal results were obtained in 30 $(85.78 \%)$ patients and sub-optimal results were obtained in 5(14.22\%) patients of whom insufficient mitral valve area observed in 3 (8.5\%) patients and mitral regurgitation was observed in 2 (5.7\%) patients. Commissural calcification has positive correlation with development of $M R$ ( $P=0.007$ ) MR has slightly inverse correlation with mobility (correlation coefficient -0.1) $(p=0.546)$ and thickness has direct correlation with development of MR ( $p=0.0000001$ coefficient 0.98) which is highly correlated. But development of MR is not correlated with pre mitral valve area overall(cc $0.189 p=.138)$ either commissure split (cc 0.108 $p=0.2684)$ bicommisural fused (cc $0.158 \mathrm{p}=0.182$ )
\end{abstract}


Percutaneous balloon mitral valvuloplasty in severe restenosis of the mitral valve: Analysis of ....

Conclusion: Commissural morphology is the most important predictor of outcomes for PBMV in restenotic valves. Adequate assessment by echocardiography improves the success of PBMV and decreases the complication rates.

Keywords: Closed mitral commissurotomy, Mitral stenosis, Percutaneous mitral valvuloplasty, Restenosis, Rheumatic heart disease

\section{Introduction:}

Rheumatic heart disease (RHD) is still a significant problem in developing countries with mitral stenosis (MS) being the most frequent manifestation (1). In India, the prevalence of rheumatic fever and RHD is 0.08 per 1000 children, while in adults the average ranges between 123 to 200 per one lakh population (2). The disease primarily affects the endocardium, leading to inflammation and scarring of the cardiac valves. Stenosis of mitral valve occurs from leaflet thickening, commissural fusion, and chordal shortening and fusion.

MS is a mechanical obstruction to forward flow and the only definitive therapy is mechanical relief of this obstruction. Three procedures are effective in providing such therapy. These are percutaneous balloon mitral valvuloplasty (PBMV), open commissurotomy, and mitral valve replacement. Because clinical trials have found PBMV to be superior to closed surgical commissurotomy, the latter procedure has been largely abandoned except in areas where it is less expensive to perform closed commissurotomy than PBMV (3-5).

Restenosis is seen in 10-20\% of cases on follow up. Cause of restenosis may be at the commissural fusion, valve leaflet thickening, sub valvular disease progression. Studies have shown that redo PBMV is an effective and comparable procedure to surgical mitral valve replacement (MVR). Two dimensional (2D) echocardiography plays a crucial role in the assessment of mitral valve morphology, hemodynamic parameters, chamber measurements and selection of appropriate therapeutic strategy. Currently this assessment is based on Wilkins score, which includes mitral valve leaflet mobility, thickening, calcification and sub valvular thickening (5). This scoring system does not include commissural morphology and calcification which are important predictors of mitral regurgitation and improvement of mitral valve area. Several models that seek to include a prediction of mitral regurgitation (MR) have been proposed, however the best combination of parameters to predict outcome variables remains to be defined (6-11).

Management of post intervention (surgery or balloon valvuloplasty) mitral valve restenosis is controversial and remains a clinical challenge. Once restenosis occurs, valve morphology and clinical parameters should guide the therapeutic approach (12). The mechanism of surgical commissurotomy, open and closed, is the same as for balloon valvuloplasty (i.e., commissural splitting). PBMV is efficacious in patients with restenosis after closed mitral commissurotomy $(\mathrm{CMC})$ (12). However, few data exist regarding the outcome of repeat PBMV after initially successful PBMV and CMC. We therefore analyzed the baseline characteristics in patients with restenosis after previous PBMV or CMC and studied the morphologic predictors of procedural success of valvuloplasty in such patients.

\section{Materials And Methods}

Aim is to study the quantitative and qualitative parameters of mitral valve apparatus by using echocardiography and to predict the feasibility, safety of PBMV, immediate and short term outcomes of the procedure in patients with severe restenosis of the mitral valve. It is a single center study conducted in the Department of Cardiology, Nizams Institute of Medical Sciences from September 2014 to November 2016. Thirty five consecutive patients who underwent PBMV for symptomatic and severe restenosis of the mitral valve were included in the study after taking informed consent. Institutional ethical committee clearance was obtained. We defined mitral restenosis as a reappearance of cardiac-related symptoms despite optimal medical therapy after initially successful CMC or PBMV associated with MVA $<1.5 \mathrm{~cm} 2$ and the loss of $>50 \%$ of the initial MVA gained in the first procedure.

Patients with persistent left atrial or left atrial appendage thrombus, more than moderate mitral regurgitation(MR), severe or bicommissural calcification, severe concomitant aortic valve disease, severe organic tricuspid stenosis, severe concomitant coronary artery disease requiring bypass surgery and severe subvalve disease were excluded from the study.

All the patients included in the study were evaluated as follows. Chief complaints like breathlessness and pedal edema were noted and history of present illness was recorded. Relevant past history, personal history and treatment history were taken. General examination was done and anthropometric recordings like height, weight, body mass index(BMI), body surface area were recorded. Vitals of the patient were noted. Cardiovascular examination was done followed by the examination of other systems.

Blood samples of patient were collected and hemoglobin, blood urea, serum creatinine random blood sugar analysis and blood grouping were done. Electrocardiogram (ECG) of patient was taken. Trans thoracic 2D echocardiographic examination including MV area $\left(\mathrm{cm}^{2}\right)$, peak gradient $(\mathrm{mmHg})$, mean gradient $(\mathrm{mm}$ of 
Percutaneous balloon mitral valvuloplasty in severe restenosis of the mitral valve: Analysis of ....

$\mathrm{Hg}$ ), right ventricular systolic pressure from tricuspid regurgitation (TR) jet, Wilkins score, commissural calcification and morphology as per American society of Echocardiography guidelines were recorded.

Transthoracic, M-mode, 2-dimensional, and doppler echocardiography were performed on the day before and within 24 hours after PBMV. All patients underwent a transesophageal echocardiography within 48 hours prior to PBMV in order to exclude the presence of left atrial thrombus and to assess valve morphology. MS was quantified by doppler measurement of trans valvular gradients and estimation of valve area by the pressure half-time method and planimetry.

The morphology of mitral valve was assessed by Wilkins scoring system based on mitral valve mobility, thickening, calcification, and sub valvular apparatus. Each parameter has a scale of 1-4. Higher scores are suggestive of unfavourable morphology. Assessment of commissural morphology was done in parasternal short axis view . To define more accurately the relation between the mechanism of restenosis and the immediate results of repeat PBMV, we focused on commissural morphology and subclassified patients into 2 groups: patients with bilateral fused commissures and patients with either unilateral or bilateral split commissures. Commissural calcification was identified by high intensity echoes casting an acoustic shadow.

MR severity was evaluated by integrating data from the color flow image, analysis of the vena contracta, and study of the pulmonary venous systolic reflux. The continuous-wave doppler TR jet velocity was used to determine systolic pulmonary artery pressure (SPAP) using the simplified Bernoulli equation assigning a value of $10 \mathrm{mmHg}$ to account for right atrial pressure. All results were based on the average of three measurements for patients in sinus rhythm and five measurements for patients in atrial fibrillation (AF).

All patients underwent transesophageal echo (TEE) before PBMV with a $5 \mathrm{MHz}$ multiplane transoesophageal probe and Philips IE 33 ultrasound scanner. The mitral valve leaflets and subvalvar apparatus were examined at mid-oesophageal and transgastric levels. The mitral commissures were scanned systematically at the mid-oesophageal level. The antero lateral commissure was visualized in the transverse plane by advancing and retracting the probe, there by scanning the length of the commissure from the leaflet tip to the annulus. The posteromedial commissure was scanned in the longitudinal plane by rotating the probe clockwise and anticlockwise.

PBMV was done with an Accura balloon catheter by the trans-septal (Brockenbrough) technique. Hemodynamic measurements include systemic blood pressure, heart rate, left atria pressure (LAP), left ventricular end-diastolic pressure (LVEDP), end diastolic gradient (EDG), mean diastolic pressure gradient (MDG) before and immediately after PBMV.

Procedural success was defined as an increase of $50 \%$ of mitral valve area or a final area of $1.5 \mathrm{~cm}^{2}$, with no more than one grade increment in MR severity assessed by echocardiography 24 hours after the procedure. Death, more than moderate mitral regurgitation grade, cardiac tamponade, and massive thromboembolism were considered major periprocedural complications.

\section{Results:}

In the present study we evaluated 35 patients who underwent PBMV for mitral restenosis. Bilateral fused commisures were in 7 patients and either of commissure was split in remaining 28 patients. Demographic, clinical and biochemical profile is shown in table 1. Baseline characteristics of bilateral fused and either open commissure groups are shown in table 2.

Table 1: Demographic and clinical characteristics of study population

\begin{tabular}{|c|c|}
\hline Characteristic & Mean \pm SD $/$ n $(\%)$ \\
\hline AGE(years) & $37.51 \pm 10.29$ \\
\hline MALE:FEMALE & $13: 22$ \\
\hline HEIGHT,(cm) & $153.62 \pm 8.12$ \\
\hline WEIGHT ,(kg) & $47.09 \pm 9.29$ \\
\hline BMI, $\left(\mathrm{kg} / \mathrm{m}^{2}\right)$ & $18.81 \pm 2.96$ \\
\hline BSA, $\left(\mathbf{m}^{2}\right)$ & $1.43 \pm 0.15$ \\
\hline PR (bpm) & $82.5 \pm 7.15$ \\
\hline SBP( $\mathrm{mm}$ of hg) & $109.1 \pm 8.50$ \\
\hline DBP( $\mathrm{mm}$ of hg) & $78.45 \pm 5.28$ \\
\hline $\mathrm{Hb}(\mathrm{gm} / \mathrm{dl})$ & $12.81 \pm 1.64$ \\
\hline RBS( mg/dl) & $99.74 \pm 38.52$ \\
\hline B. Urea( mg/dl) & $26.14 \pm 7.44$ \\
\hline S.Creatinine( $\mathrm{mg} / \mathrm{dl})$ & $0.76 \pm 0.21$ \\
\hline
\end{tabular}

$\mathrm{BMI}=$ body metabolic index, $\mathrm{BSA}=$ body surface area, $\mathrm{PR}=$ pulse rate, $\mathrm{SBP}=$ systolic blood pressure, $\mathrm{DBP}=$ diastolic blood pressure, $\mathrm{Hb}=\mathrm{Hemoglobin}, \mathrm{RBS}=$ random blood sugar, $\mathrm{B} . \mathrm{UREA}=\mathrm{blood}$ urea, s.creatinine= serum creatinine 
Percutaneous balloon mitral valvuloplasty in severe restenosis of the mitral valve: Analysis of ....

Table 2: Comparison of baseline characteristics of either commissure split and fused groups

\begin{tabular}{|lccc|}
\hline \multicolumn{1}{c}{ Variable } & Either commissure split $(\mathbf{n = 2 8})$ & Bilateral fused commissure $(\mathbf{n}=\mathbf{7})$ & P value \\
\hline Age in yrs(mean) & $37.51 \pm 10.14$ & $37.44 \pm 9.27$ & 0.83 \\
\hline Female & 18 & 04 & 0.72 \\
Male & 10 & 03 & 0.68 \\
\hline Atrial Fibrillation & 07 & 04 & 0.17 \\
\hline Past history of PBMV & 06 & 01 & 0.67 \\
\hline Time gap from last procedure & 9.71 & 9.61 & 0.477 \\
\hline Past history of CMC & 08 & 01 & 0.43 \\
\hline
\end{tabular}

PBMV- Percutaneous balloon mitral valvuloplasty, CMC closed mitral commissurotomy .

Study population included patients with age 18 to 64 years. Mean age of the study population was $37.51 \pm 10.29$ years. Majority of patients were in the age group of 30-45 years. Mean age of patients in bilateral fused commisures group was $37.44 \pm 9.27$ years and in the either commissure split outcomes group was $37.51 \pm 10.14$ years. There was no significant statistical difference in age between two groups $(\mathrm{p}=0.83)$

Out of 35 patients, $22(62.8 \%)$ were females and 13(37.2\%) were males. In bilaterally fused commisures group, out of 7 patients, $4(57 \%)$ were females and 3(43\%) were males. In either commissure split group $(n=28), 18(64.2 \%)$ were females and $10(35.71 \%)$ were males. However there was no significant gender difference between two groups $(\mathrm{P}=0.83)$

The most common presenting complaint was dyspnea, which was present in $99 \%(\mathrm{n}=33)$ of the patients. Eleven $(31.4 \%$ ) patients presented with palpitations (due to AF with fast ventricular rate). One (2.8\%) patients presented with hemoptysis and chest pain was present in $6(17.1 \%)$ patients. Past history of rheumatic fever was present in $14(40.0 \%)$ patients. Nine $9(25.71 \%)$ patients had undergone history of Closed Mitral Valvolotmy as first procedure. Seven (20\%) patients underwent 2 previous procedures. History of a cerebrovascular accident was present in 1 patient. There is no statistical difference between the groups.

Mean mitral valve area was $1.02 \pm 0.15\left(\mathrm{~cm}^{2}\right)$ and $1.07 \pm 0.19\left(\mathrm{~cm}^{2}\right)$ in either commissure split and bilateral fused commisures groups respectively $(\mathrm{p}=0.23)$. Mean mitral valve gradient, peak mitral valve gradient, systolic pulmonary artery pressure and LA size were not statistically significant between two groups. LA thrombus was absent in both the groups. Pre-procedural transthoracic echocardiographic parameters are shown in table 3 .

Table 3: Preprocedure transthoracic echocardiographic parameters

\begin{tabular}{|llll|}
\multicolumn{1}{|c|}{ Parameter } & Either commissure split group & \multicolumn{1}{c|}{$\begin{array}{c}\text { Bilateral fused commissure } \\
\text { group }\end{array}$} \\
\hline Mean mitral valve gradient(mmhg) & $13.86 \pm 5.56$ & $12.00 \pm 2.83$ & 0.40 \\
\hline Peak mitral valve gradient(mmHg) & $22.75 \pm 6.44$ & $20.57 \pm 4.65$ & 0.40 \\
\hline $\begin{array}{l}\text { Systolic pulmonary artery } \\
\text { pressure }\left(\mathbf{m m H g}^{\prime}\right)\end{array}$ & $47.93 \pm 12.95$ & $45.86 \pm 15.13$ & \\
\hline MV area $\left(\mathbf{c m}^{\mathbf{2}}\right)$ & $1.02 \pm 0.15$ & $1.07 \pm 0.19$ & $<.71$ \\
\hline LA size & $3.99 \pm 0.54$ & $4.06 \pm 0.28$ & $<0.23$ \\
\hline
\end{tabular}

MV AREA=mitral valve area. $\mathrm{LA}=$ left atrium

In this study average post PBMV mitral valve area in bilateral fused commisures group was $1.77 \pm 0.09$ $\mathrm{cm}^{2}$ and in either of commissure split group was $1.52 \pm 0.42 \mathrm{~cm}^{2}(\mathrm{p}=0.001)$. Mean mitral valve gradients were $5.04 \pm 1.69 \mathrm{mmHg}$ and $3.71 \pm 4.08 \mathrm{mmHg}(\mathrm{p}=0.025)$ and peak mitral valve gradient was $9.54 \pm 2.52$ and $7.14 \pm 3.39$ $(\mathrm{p}=0.02)$ which are statistically significant in either commissure split and bilateral fused commisures group respectively. There was no statistically significant difference in, systolic pulmonary artery pressures between the two groups. Post-procedural transthoracic echocardiac parameters are shown in table 4.

Table 4: Post procedure echocardiographic parameters

\begin{tabular}{|lccc|} 
& $\begin{array}{c}\text { Either commissure split } \\
\text { group }\end{array}$ & $\begin{array}{c}\text { Bilateral fused commissure } \\
\text { group }\end{array}$ & p-value \\
\hline Mean MV Gradient(mmHg) & $5.04 \pm 1.69$ & $3.71 \pm 4.08$ & 0.025 \\
\hline Peak MV Gradient(mmHg) & $9.54 \pm 2.52$ & $7.14 \pm 3.39$ & 0.02 \\
\hline S PAP(mmHg) & $37.29 \pm 8.48$ & $39.29 \pm 9.44$ & 0.26 \\
\hline MVA $\left.\quad \mathbf{( c m}^{2}\right)$ & $1.52 \pm 0.42$ & $1.77 \pm 0.09$ & 0.001 \\
\hline
\end{tabular}

$\mathrm{MV}=$ Mitral valve, LA V=left atrial volume, SPAP=systolic pulmonary artery pressure, MVA=mitral valve area.

Post PBMV left atrium (LA) mean pressure in bilateral fused commisures group was $8.43 \pm 4.66 \mathrm{mmHg}$, and either of the commissure split group was $11.71 \pm 3.72 \mathrm{mmHg}$ which was statistically significant difference $(\mathrm{p}=0.02)$ (Table 5). 
Table 5: Cardiac catheterization data

\begin{tabular}{|c|c|c|c|}
\hline Variable & $\begin{array}{l}\text { Either commissure } \\
\text { open group }\end{array}$ & $\begin{array}{l}\text { Bilateral fused } \\
\text { commissure group }\end{array}$ & P value \\
\hline Pre LA mean pressure (mmhg) & $19.72 \pm 5.85$ & $20.89 \pm 6.55$ & 0.27 \\
\hline Post LA mean pressure (mmhg) & $11.71 \pm 3.72$ & $8.43 \pm 4.66$ & 0.02 \\
\hline Pre LVEDP (mmhg) & $8.89 \pm 1.74$ & $8.71 \pm 1.60$ & 0.44 \\
\hline Post LVEDP (mmhg) & $7.29 \pm 3.85$ & $6.29 \pm 5.62$ & 0.18 \\
\hline
\end{tabular}

LA =left atrium, LVEDP= left ventricular end diastolic pressure

Among 35 patients, 25 were in low risk group (Wilkin's score score: $\leq 8$ ), 10 were in high risk group (score: >8). The box plot (Fig 1) shows the distribution of Wilkins Score in split and fused groups. There is a tendency for higher Wilkins score in fused group compared to split group.

Fig 1: Distribution of patients according to Wilkins score in either split and bilateral fused groups

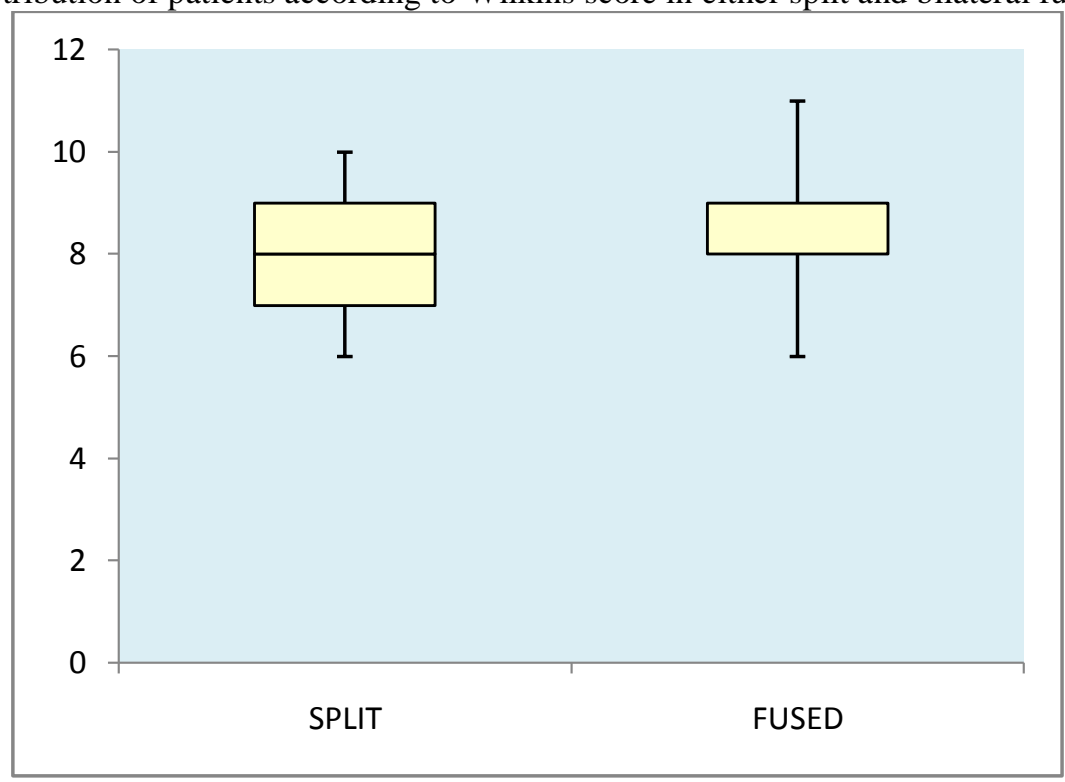

Optimal procedural results were obtained in $30(85.78 \%)$ patients and sub-optimal results were obtained in $5(14.22 \%)$ patients of whom insufficient mitral valve area was observed in $3(8.5 \%)$ patients and mitral regurgitation was observed in $2(5.7 \%)$ patients. Post PBMV mitral valve area was higher in patients with fused commissures and was statistically significant.

There was statistically significant negative correlation between optimal outcome and mitral leaflet thickness, valve calcification, and high Wilkins scores and commissural calcification. There is a statistically significant positive correlation of optimal outcome with pre mitral valve area leaflet mobility and bicommisural fusion (table 6).

Table 6: Correlation between echocardiographic parameters and outcomes

\begin{tabular}{|lcc|}
\hline \multicolumn{1}{|c|}{ OUTCOME } & Correlation coefficient $(\mathbf{r})$ & p-val \\
\hline Thickness & 0.128 & $-0.05^{*}$ \\
\hline Calcium & 0.048 & $0.39^{*}$ \\
\hline Leaflet mobility & 0.856 & 0.003 \\
\hline Subvalvular thickness & 0.218 & 0.100 \\
\hline Wilkins score & 0.470 & $-0.0022^{*}$ \\
\hline MVA & 0.8569 & $0.0001^{*}$ \\
\hline Commisural calcium & 0.371 & -0.04 \\
\hline Commisural morphology & 0.92 & 0.002 \\
\hline
\end{tabular}

Max= maximum, MVA=mitral valve area.

Commissural calcification has positive correlation with development of MR ( $\mathrm{P}=0.007$ ) MR has slightly inverse correlation with mobility (correlation coefficient -0.1) $(\mathrm{p}=0.546)$ and thickness has direct correlation with development of MR ( $\mathrm{p}=0.0000001$ coefficient 0.98$)$ which is highly correlated . But development of MR is not correlated with pre mitral valve area overall(cc $0.189 \mathrm{p}=.138$ ) either commissure split (cc $0.108 \mathrm{p}=0.2684$ ) bicommisural fused (cc $0.158 \mathrm{p}=0.182)$ (table 7). 
Table 7: Correlation between echocardiographic parameters and development of MR

\begin{tabular}{|lcc|}
\hline \multicolumn{1}{|c}{ Mitral regurgitation } & Correlation coefficient (r) & P value \\
\hline Thickness & 0.8046 & 0.000001 \\
\hline Commissural calcification & 0.98 & 0.007 \\
\hline Leaflet mobility & -0.1 & 0.545972 \\
\hline Subvalvular thickness & 0.580 & 0.375 \\
\hline Wilkins score & 0.856 & 0.0001 \\
\hline Either commissure split & 0.108 & 0.268 \\
\hline Bicommissural fusion & 0.158 & 0.182 \\
\hline MVA & 0.189 & 0.138 \\
\hline
\end{tabular}

Max= maximum, MVA=mitral valve area.

Regression analysis showed that valve calcification Commissural calcification have negative regression with $\mathrm{B}$ value .Valve thickness and subvalvular disease are neutral in regression. Commissural morphology (bicommissural fusion) \& leaflet mobility have independent positive regression with B value for optimal PTMC outcomes (table 8).

Table 8: Regression analysis for outcomes

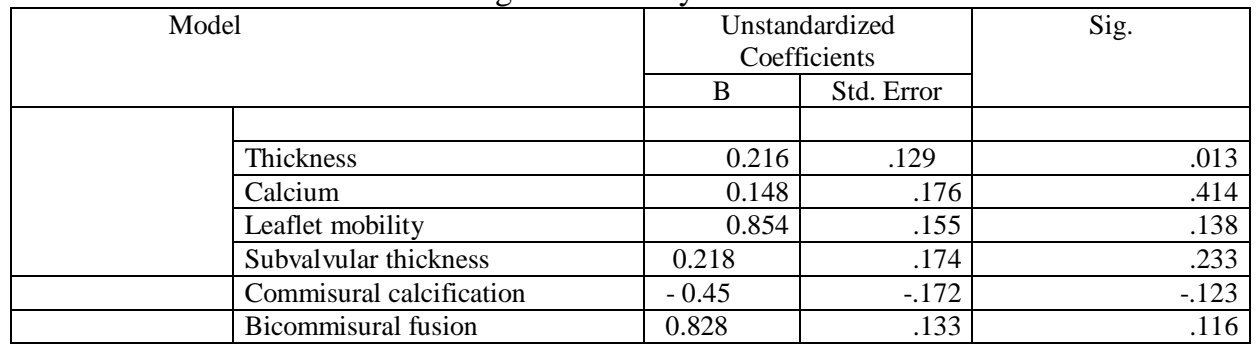

Commissural calcification has high positive regression with development of mitral regurgitation. But valve calcification and valve thickness only mild positive regression with development of MR. Other variables like subvalvular disease and leaflet mobility and bicommissural fusion have no regression with MR (table 9).

Table 9: Regression analysis for prediction of mitral regurgitation

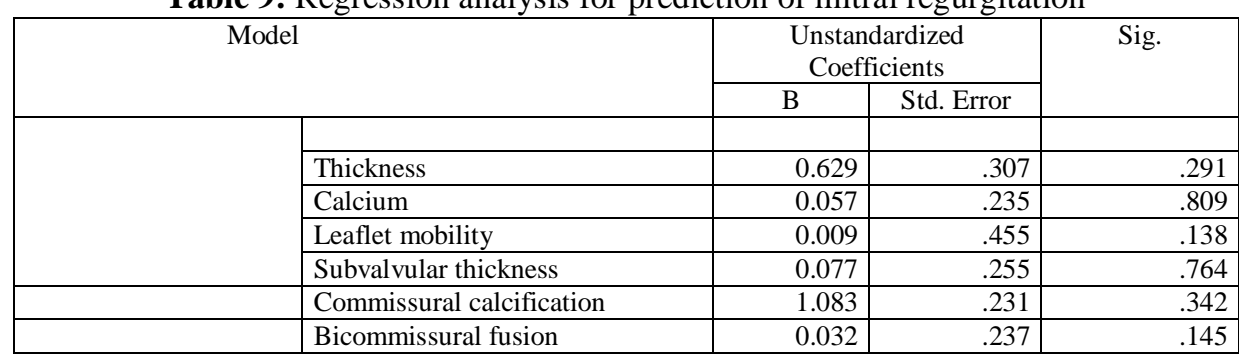

Three 3 patients developed moderate to severe MR, out of which one patient required emergency mitral valve replacement. None of the other major complications were noted.

\section{Discussion:}

In this study, we observed that patients with bilaterally fused commisures have greater increase in valve area have greater decrease in peak gradient and mean gradient with PTMC. Patients with bilaterally fused commisures have greater decrease in post PBMV LA mean pressure. Low Wilkins Score, and bilateral fused commissural morphology have positive correlation with outcomes. In high wilkins score group individual parameters like less mitral valve thickness and more mobility are positive correlates with outcome.

Previous MV intervention was not associated with sub optimal outcomes, similar to the findings of Guptha et al who analysed 614 consecutive patients undergoing REDO PTMC including 8 patients (13.2\%) with second mitral restenosis following prior surgical valvotomy(13). They found that percutaneous balloon mitral valvotomy can be performed safely and effectively in patients with mitral restenosis following surgical valvotomy.

In our study, patients who had successful PBMV had lower Wilkin's score, and bilaterally fused commissural morphology $(6,12)$, consistent with the findings of Turgeman, et al and Hung, et al who demonstrated that a more abnormal echocardiographic morphology predicted less symptomatic improvement and had a smaller post procedure valve area $(9,13)$. 
In this study, we found that valvular thickening was the negative echocardiographic predictor of absolute change in valve area, which is in contrast with Abascal et al (7) who studied 130 consecutive patients with MS who underwent PBMV for first time. Also we found that leaflet mobility and pre PBMV valve area were predicting the outcomes which is consistent with the findings of Reid et al (8), who analyzed 555 patients with MS and found that leaflet motion was the most significant predictor of post procedure valve area in first PBMV procedure.

Subvalvular pathology did not result in sub optimal outcomes after PBMV which was contrary to the findings of Parag Bhalgat et al who studied 356 patients who had undergone PTMC for valvular stenosis or restenosis (14). This bias is due to excluding patients with severe sub valvular disease in our study.

In our study, MR developed after PBMV in $3(8.5 \%)$ of patients and these findings are similar to Padial et al who studied 566 patients, of whom >2+ MR developed in $6.5 \%$ patients (15). In another study by Vahanian et al who studied 189 patients, >2+ MR developed in 7\% of patients (14). A large series from India by Kaul UA et al, reported that $8.4 \%$ developed $>2+$ MR ,of which $3.3 \%$ patients developed severe MR and required $\operatorname{MVR}(16)$.

In the present study Wilkin's score found correlation with development of MR ( $\mathrm{cc}=0.8)$. This finding is similar to observer of Abascal et al who also found a correlation between development of MR and higher Wilkins score. Fatkin et al demonstrated the influence of commissural calcification on the short-term outcome in a series of 30 patients undergoing first PBMV (13). Subsequently, Cannan et al studied 149 patients and found that presence of commissural calcification as identified by 2D echocardiography was a useful predictor of outcome after first PTMC. Patients with evidence of commissural calcium had a lower survival rate and a higher incidence of MVR at intermediate follow-up. Agarwal BL et al reported that patients with bilateral commissural split had more favorable hemodynamic results with lower transmitral gradients, greater mitral valve area and lesser frequency of MR in contrast to our study where PBMV outcomes were better with bilateral fused commisures than split commisures (18).

This is a single center study with a relatively small sample size, hence, it is difficult to generalize our results. TEE was not repeated routinely after PBMV. The commissural morphology is visually assessed by single operator in TTE, and actual comparison of this qualitative and objective score was not done with TEE . There is no long term follow up of the patients. These are the limitations of the study.

\section{Conclusion:}

PBMV can be safely performed in patients with restenosis of the mitral valve with minimal complications. Commissural morphology is the most important predictor of outcome in patients undergoing PBMV for mitral restenosis. Comprehensive echocardiographic examination is mandatory for selection of patients. Lower mitral valve thickness and higher mobility has positive correlation with optimal outcomes. Commissural calcification and high leaflet thickness predict the development of mitral regurgitation. Previous MV intervention type (CMV/PTMC), time gap from previous intervention, age, body surface area, gender and atrial fibrillation are not associated with outcomes.

\section{References:}

[1]. Marijon E, Mirabel M, Celermajer DS, Jouven X. Rheumatic heart disease. Lancet. 2012; 379:953-964

[2]. Mathur KS, Wahal PK. Epidemiology of rheumatic heart disease-a study of 29,922 school children. Indian heart Journal. 1982; 34:367-71.

[3]. Reyes VP, Raju BS, Wynne J, Stephenson LW, Raju R, Fromm BS, Rajagopal P, Mehta P, Singh S, Rao DP. Percutaneous balloon valvuloplasty valvuloplasty compared with open surgical commissurotomy for mitral stenosis. N Engl J Med. 1994;331:961-967.

[4]. Ben Farhat M, Ayari M, Maatouk F, Betbout F, Gamra H, Jarra M, Tiss M, Hammami S, Thaalbi R, Addad F. Percutaneous balloon versus surgical closed and open mitral commissurotomy: seven-year follow-up results of a randomized trial. Circulation. 1998;97:245-250.

[5]. Raju S Iyer, Rajnish Jain, Manoj Padmanabhan, Abha Chandra, Sanjeev Agarwal, Raja Sekhar D, et al. Closed Mitral Valvotomy versus Balloon Valvuloplasty: A Comparison of 100 Cases. Asian Cardiovascular and Thoracic Annals 1998; 6:285-287.

[6]. Wilkins GT, Weyman AE, Abascal VM, Block PC, Palacios IF. Percutaneous balloon dilatation of the mitral valve: an analysis of echocardiographic variables related to outcome and the mechanism of dilatation. Br Heart J. 1988; 60:299-308.

[7]. Abascal VM, Wilkins GT, O'Shea JP, Choong CY, Palacios IF, Thomas JD, Rosas E, Newell JB, Block PC, Weyman AE. Prediction of successful outcome in 130 patients undergoing percutaneous balloon mitral valvotomy. Circulation. 1990;82:448-456.

[8]. Reid CL, Chandraratna PA, Kawanishi DT, Kotlewski A, Rahimtoola SH. Influence of mitral valve morphology on double-balloon catheter balloon valvuloplasty in patients with mitral stenosis. Analysis of factors predicting immediate and 3-month results. Circulation. 1989;80:515-524.

[9]. Feasibility, Safety, and Morphologic Predictors of Outcome of Repeat Percutaneous Balloon Mitral Commissurotomy Yoav Turgeman, MD, Shaul Atar, MD, Khalid Suleiman, MD, Alexander Feldman, MD, Lev Bloch, MD, Mohamed Jabaren, MD, and Tiberio Rosenfeld, MD (Am J Cardiol 2005;95:989-991)

[10]. Anwar AM, Attia WM, Nosir YF, Soliman OI, Mosad MA, Othman M, Geleijnse ML, El-Amin AM, Ten Cate FJ. Validation of a new score for the assessment of mitral stenosis using real-time three-dimensional echocardiography. J Am Soc Echocardiogr. 2010;23:13-22.

[11]. Nunes et al.;Impact of Incorporating Commissural Morphology and Leaflet Displacement to the Prediction of Outcome for Patients Undergoing Percutaneous MitralValvuloplasty. Circulation.2013.113.001252 
[12]. Redo percutaneous mitral valvuloplastyfor mitral restenosis: a comparison with first procedure for de novo mitral stenosis Osama Rifaie, Mohamed Ismail, Mohamed Helmy, Mohamed El-Bialy, Wail Nammas. Kardiol Pol 2011;69(2):125-131

[13]. Gupta S, Vora A, Lokhandwalla Y, et al. Percutaneous balloon mitral valvotomy in mitral restenosis. Eur Heart J 1996;17:1560 4.

[14]. Bhalgat $\mathrm{P}$ et al, Subvalvular apparatus and adverse outcome of balloon valvotomy in rheumatic mitral stenosis. Indian Heart J. 2015 Sep-Oct;67(5):428-33.

[15]. Hung JS, Chern MS, Wu JJ, Fu M, Yeh KH, Wu YC, Cherng WJ, Chua S, Lee CB. Am J Cardiol. 1991 Apr 15;67(9):854-62.

[16]. Kaul UA, Singh S, Kalra GS, et al. Mitral regurgitation following percutaneous transvenous mitral commissurotomy: A singlecenter experience. J Heart Valve Dis 2000;9:262-266.

[17]. Fatkin D, Roy P, Morgan JJ, Feneley MP. Percutaneous balloon mitral valvotomy with theinoue single-balloon catheter: Commissural morphology as a determinant of outcome. J Am Coll Cardiol. 1993;21:390-397.

[18]. Agarwal, B.L., Kapoor, A., Singh, R., Tewari, S., Radhakrishnan, S., Shrivastava, S. et al, Predictive accuracy of commissural morphology and its role in determining the outcome following Inoue balloon mitral valvotomy. Indian Heart J. 2002;54:39-45.

Srinivas Bhyravavajhala. "Percutaneous balloon mitral valvuloplasty in severe restenosis of the mitral valve: Analysis of factors affecting the short term outcomes - A single center experience." IOSR Journal of Dental and Medical Sciences (IOSR-JDMS) 16.7 (2017): 27-34. 